\title{
Modeling of Two-Phase Flow through a Rotating Tube with Twin Exit Branches
}

\author{
SUN-WEN CHENG* and WEN-JEI YANG \\ Department of Mechanical Engineering and Applied Mechanics, University of Michigan, Ann Arbor, MI 48109, USA
}

(Received 8 May 1998; In final form 3 August 1998)

\begin{abstract}
A numerical model is proposed to determine the dynamic behavior of single-phase and twophase, two-component flows through a horizontal rotating tube with identical twin exit branches. The working fluid, oil, enters the tube through a radial duct attached at one end and exits into open air through the twin radial branches, one located at midway and the other at the end of the tube. The branch-to-tube diameter ratio, rotational speed, and total oil flow rate are varied. It is experimentally revealed in previous study that the air cavitation occurs at lower speeds, leading to a two-phase flow with the air-oil ratio (void fraction) varying with the rotating speed. A unique characteristic in two-phase flow, i.e., hysteresis, is found to exist in both oil flow rates and inlet pressure. In theoretical modeling, the governing flow equations are incorporated by empirical equations for hydraulic head losses. The predicted and measured exit oil flow rates are compared with good agreement in both the single-phase and annular flow regimes. Only qualitative agreement is achieved in the bubbly and bubbly-slug flow regimes. The model can be applied to improve the design and thus enhance the performance of automatic transmission lines, and the cooling efficiency of rotating machines and petroleum drilling process.
\end{abstract}

Keywords: Rotating tube, Twin exit branches, Air-oil flow, Hysteresis, Lubrication, Modeling

\section{INTRODUCTION}

To achieve a high efficiency or working requirement, rotary devices such as automatic transmission lines in automobiles are designed to operate at high rotational speeds. A lubricant or coolant is supplied through a hollow shaft to surrounding mechanical parts. Evaluation of the liquid discharge rate is a great challenge because theoretical solu- tions and empirical correlations for fluid flow in stationary piping are not applicable. A well-known theory of the electric circuit analogy that pressure drop or hydraulic head loss is similar to electric resistance could solve the problem if flow remains single-phase (Backe, 1973). But air cavitation occurs if there is an opening or more to an air reservoir or atmosphere (Cheng and Yang, 1996). The intruding air blocks the flow passage and reduces the

\footnotetext{
* Corresponding author. Lucent Technologies Power Systems, 3000 Skyline Drive, Mesquite, TX 75149, USA. Tel.: 9722844245.
} E-mail: cscheng@lucent.com. 
discharge rate to one or several parts under certain operating conditions. Furthermore, the air causes hysteresis in the liquid flow rate and pressure (Cheng and Yang, 1997). The two-phase flow patterns depend on the input liquid flow rate, rotational speed, passage dimensions and spinning process. Experiment takes time to do a systematic investigation. Numerical simulation is a better way to assist design process.

So far only Kojima et al. (1991) have studied annular flow in an axially rotating shaft, and Uchiyama et al. (1994) simulated bubbly flow in a radially rotating branch. However, their methods cannot predict two-phase flow behavior in a flow network featuring both the axial and radial channels in rotation. This paper presents a numerical approach to obtain the exit oil flow rates of the system.

\section{ASSUMPTIONS AND GOVERNING EQUATIONS}

A schematic of the flow passage is shown in Fig. 1. Numbers label the stations to calculate local pressures. The dimensions of flow passage treated in this paper is listed in Table I. Several assumptions are made as follows:

(a) incompressible, laminar, isothermal, and steady-state conditions,

(b) constant fluid physical properties,

(c) negligible gravity effect,

(d) axial and radial rotations only,

(e) fully-developed rotating flow,

(f) axial symmetry in the tube, and

(g) considerable pressure gradient in the throughflow direction of the tube.

The governing equations in vector forms are: continuity:

$$
\nabla \cdot \bar{U}=0
$$

momentum:

$$
(\bar{U} \cdot \nabla) \bar{U}+2 \bar{W} \times \bar{U}=\frac{-1}{\rho} \nabla P^{*}+\nu \nabla^{2} \bar{U},
$$

TABLE I Dimensions of flow passage (unit: $\mathrm{mm}$ )

\begin{tabular}{lcccc}
\hline Test section & Entrance & Branch A & Branch B & Tube \\
\hline ID & \multicolumn{4}{c}{} \\
$\quad$ \#1 & 6.35 & 3.175 & 3.175 & 12.7 \\
$\# 2$ & 6.35 & 6.35 & 6.35 & 12.7 \\
Length & 25.4 & 25.4 & 25.4 & 469.9 \\
Distance & \multicolumn{2}{c}{203.2} & 203.2 & \\
\hline
\end{tabular}

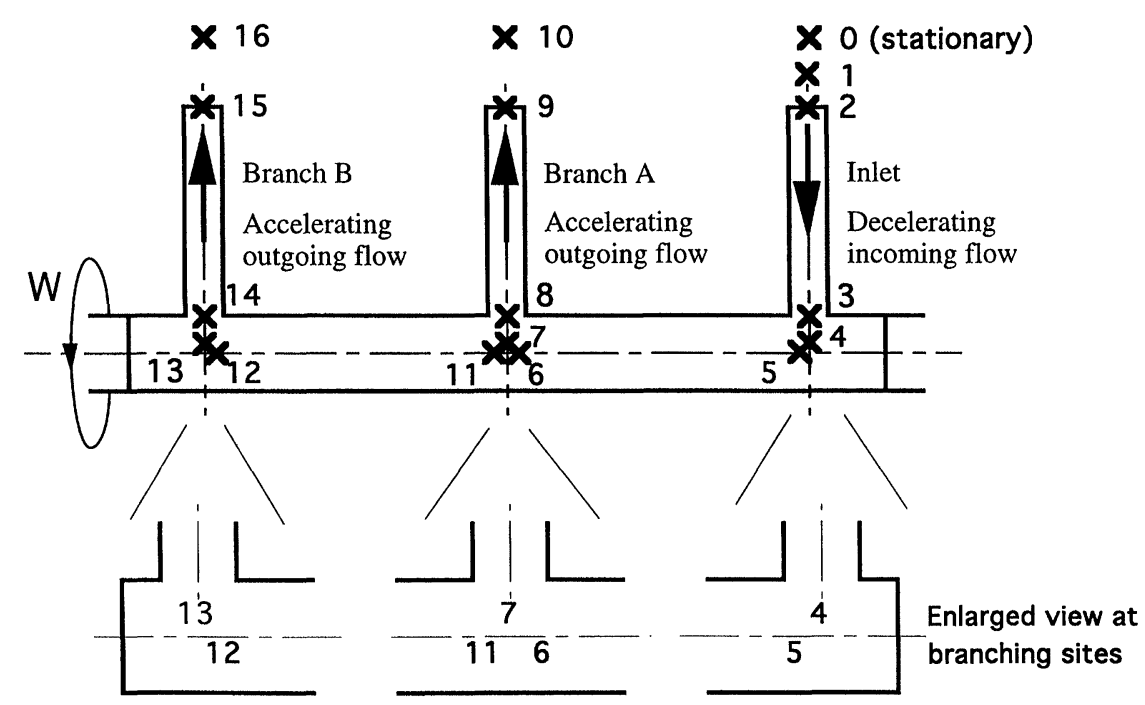

FIGURE 1 Stations of local pressure calculations in a rotating shaft with a radial inlet and twin exit branches. 
where the reduced pressure is defined as

$$
P^{*}=P-\left(\rho W^{2} \bar{r}^{2}\right) / 2
$$

and the corresponding boundary conditions on the wall, interface and centerline are:

Tube:

(i) $r=r_{\mathrm{W}}$ :

$$
\left(u_{r}\right)_{\mathrm{L}}=\left(u_{z}\right)_{\mathrm{L}}=0, \quad\left(u_{\theta}\right)_{\mathrm{L}}=r_{\mathrm{w}} W,
$$

(ii) $r=r_{\mathrm{i}}$ :

$$
\begin{aligned}
& \left(u_{r}\right)_{\mathrm{L}}=\left(u_{r}\right)_{\mathrm{G}}=0, \quad\left(u_{z}\right)_{\mathrm{L}}=\left(u_{z}\right)_{\mathrm{G}}, \\
& \left(u_{\theta}\right)_{\mathrm{L}}=\left(u_{\theta}\right)_{\mathrm{G}}
\end{aligned}
$$

and

$$
\left(\tau_{r z}\right)_{L}=\left(\tau_{r z}\right)_{G}, \quad\left(\tau_{r \theta}\right)_{L}=\left(\tau_{r \theta}\right)_{\mathrm{G}},
$$

where

$$
\tau_{r z} \equiv-\mu\left(\partial u_{z} / \partial r\right), \quad \tau_{r \theta} \equiv-\mu r\left[\partial\left(u_{\theta} / r\right) / \partial r\right],
$$

(iii) $r=0$ :

$$
u_{r}=u_{\theta}=\left(\partial u_{z} / \partial r\right)=0
$$

Branches:

(i) $r=r_{\mathrm{w}}$ :

$$
u_{r}=u_{z}=u_{\theta}=0,
$$

(ii) $\theta=0, \pi$ :

$$
u_{\theta}=0 \quad \text { and } \quad \partial u_{r} / \partial \theta=\partial u_{z} / \partial \theta=0
$$

where the subscript i denotes interface if two-phase flow appears. The two-phase flow patterns in the exit branches are too complicated to describe the interfacial boundary conditions. Homogeneous flow model is assumed valid so that the simulation results of single-phase flow can be adapted.

\section{MODELING}

Basically, the pressure drop from Station 0 to 10 is assumed to equal that from Station 0 to 16 , although in reality a slight difference exist and can cause air cavitation. The total pressure drop is expressed as:

$$
\begin{aligned}
\Delta P= & P_{\text {inlet }}-(\Delta P)_{\text {entrance }}-(\Delta P)_{\text {tube }} \\
& -(\Delta P)_{\text {junction }}+(\Delta P)_{\text {centrifugal }} \\
& -(\Delta P)_{\text {branch }}-P_{\text {ambient }} .
\end{aligned}
$$

In general, $\Delta P$ should be zero. However, the outflow is not a free jet because it hits on the surrounding wall or mechanical parts. An additional term is thus added to the right-hand side of Eq. (11)

$$
P_{\text {stag }}=n \rho_{\mathrm{L}} u_{\mathrm{x}}^{2} / 2
$$

where $u_{\mathrm{x}}$ denotes the average flow velocity inside Branch $\mathrm{A}$ or $\mathrm{B}$; and $n$, an empirical coefficient equal to $\frac{1}{4}$ for the present study.

The pressure change due to the centrifugal acceleration, major and minor head loss are calculated by the following forms:

$$
\begin{gathered}
\Delta P=\rho_{\mathrm{L}} L^{2} W^{2} / 2, \\
\Delta P=\rho_{\mathrm{L}} f\left(L u^{2} / 4 r\right), \\
\Delta P=\rho_{\mathrm{L}} K u^{2} / 2,
\end{gathered}
$$

where $L$ is the duct or branch length; $f$ the friction factor; and $K$, the minor head loss coefficient. $K$ equals 0.5 for a square-edged inlet port, and is obtained for $T$ junctions by:

combining flow type from inlet to tube:

$$
K=1.038\left(A_{\text {in }} / A_{\text {tube }}\right)^{-1.9463},
$$

dividing flow type for throughflow:

$$
\begin{aligned}
K= & 0.40143-0.79429\left(u_{\mathrm{up}} / u_{\mathrm{dn}}\right) \\
& +0.39286\left(u_{\mathrm{up}} / u_{\mathrm{dn}}\right)^{2}
\end{aligned}
$$

and dividing flow type from tube to branch:

$$
\begin{aligned}
K= & 0.98797+0.12991\left(u_{\text {tube }} / u_{\mathrm{x}}\right) \\
& +0.64608\left(u_{\text {tube }} / u_{\mathrm{x}}\right)^{2}
\end{aligned}
$$


The friction factor for radially rotating, singlephase, fully-developed, laminar flow is correlated by Ishigaki (1994):

$f / f_{\mathrm{o}}=\left(\operatorname{Re}_{\mathrm{Ne}}\right)^{0.25}\left[0.0899+1.11\left(\operatorname{Re}_{\mathrm{Re}}\right)^{-0.351}\right]$,

where $f_{\mathrm{o}}=64 / \mathrm{Re}_{\mathrm{x}}$. Equation (19) is applied to calculate the pressure drop in the branches without solving the velocity. The velocity profile in the tube is solvable and the maximum locates on the air-oil interface. The average diameter of an air bubble, slug or core is estimated by the balance of the surface tension and inertial force in the tube. Because $Q_{\mathrm{T}}$ decreases as the oil film becomes thinner, the tension and inertia are of the same importance (Cheng and Yang, 1997). The Weber's number that describe the balance is defined as:

$$
\mathrm{We}=\rho_{\mathrm{L}} u^{2} r_{\mathrm{G}} / \sigma
$$

Here, We equals 1, 1.5 and 2 for bubbly, slug and annular flow, respectively. The diameter is thus iteratively determined. The pressure drop in the tube is simpler for single-phase and annular flow regimes. The pressure drop for bubbly and bubblyslug flow regimes must be divided into three parts: single-phase, bubbly and slug sections. The one in the slug section is the same as that for annular flow regime, while the one in the bubbly slug is calculated by:

$$
\begin{aligned}
& \Delta P_{\text {bubbly }} \\
& \quad=\frac{8 N r_{\mathrm{i}} \mu_{\mathrm{L}} Q_{\mathrm{B}}}{\pi}\left[r_{\text {tube }}\left(r_{\text {tube }}^{2}-r_{\mathrm{i}}^{2}\right)-\frac{r_{\text {tube }}^{4}-r_{\mathrm{i}}^{4}}{2}\right]^{-1},
\end{aligned}
$$

where $N$ is the nearest integer to the calculation of the tube length divided by 2 and the bubble diameters, i.e., by assuming the equal distance between air bubbles and liquid space.

The branch root is not always wetted by oil. The void fraction is calculated as if oil particles "fall" into the branch exerted by the centrifugal acceleration instead of gravity and form a "moon-shape" shape. The oil travel distance from the upstream edge of the branch root is:

$$
L_{\text {td }}=\left[u_{\text {tube }}\right]_{\max }\left\{\ln \left[r_{\text {tube }}+\sqrt{r_{\text {tube }}^{2}-r_{\mathrm{i}}^{2}}\right]-\ln r_{\mathrm{i}}\right\} / W .
$$

Hence the void fraction is:

$$
\alpha=1-\frac{2 \tan ^{-1}\left(2 h / L_{\mathrm{td}}\right)}{\pi}+\frac{L_{\mathrm{td}} h}{\pi r_{\mathrm{x}}^{2}},
$$

where $h=\sqrt{4 r_{\mathrm{x}}^{2}-L_{\mathrm{td}}^{2}} / 2$. The flow velocity in the branch is hence obtained by:

$$
u_{\mathrm{x}}=\sqrt{\frac{2\left(P_{\text {root }}-P_{\text {exit }}-H g+P_{\text {centrifugal }}\right)}{\rho_{\mathrm{L}}}},
$$

where the head loss is equal to the negative value of the pressure increase:

$$
H=-\rho_{\mathrm{L}} f \frac{L-r_{\text {tube }}}{2 r_{\mathrm{x}}} \frac{u_{\mathrm{x}}^{2}}{2 g} .
$$

Then the oil outflow rate can be estimated by:

$$
Q_{\mathrm{x}}=u_{\mathrm{x}} C_{12}\left(\pi d_{\mathrm{x}}^{2} / 4\right) \text {. }
$$

This value is iteratively compared with a given inflow rate until the error is less than a tolerance.

The flow chart for simulation of annular flow is shown in Fig. 2. Both $Q_{\mathrm{T}}$ and $P_{\text {in }}$ are obtained from experimental measurements.

\section{RESULTS AND DISCUSSION}

In the interest of brevity, only the measured and predicted exit oil flow rates at $Q_{\mathrm{T}-\mathrm{ini}}=1135.5 \mathrm{~cm}^{3} /$ min $(0.3 \mathrm{GPM})$ are presented. Figures 3 and 4 illustrate the results under various rotational speeds and spin processes. Transitions of flow regimes are marked by dashed lines.

\section{Test Section \#1 (Fig. 3)}

In the spin-up process, $Q_{\mathrm{A}}$ and $Q_{\mathrm{B}}$ are well predicted in the single-phase regime (in short, $\mathrm{SF}$ ). 


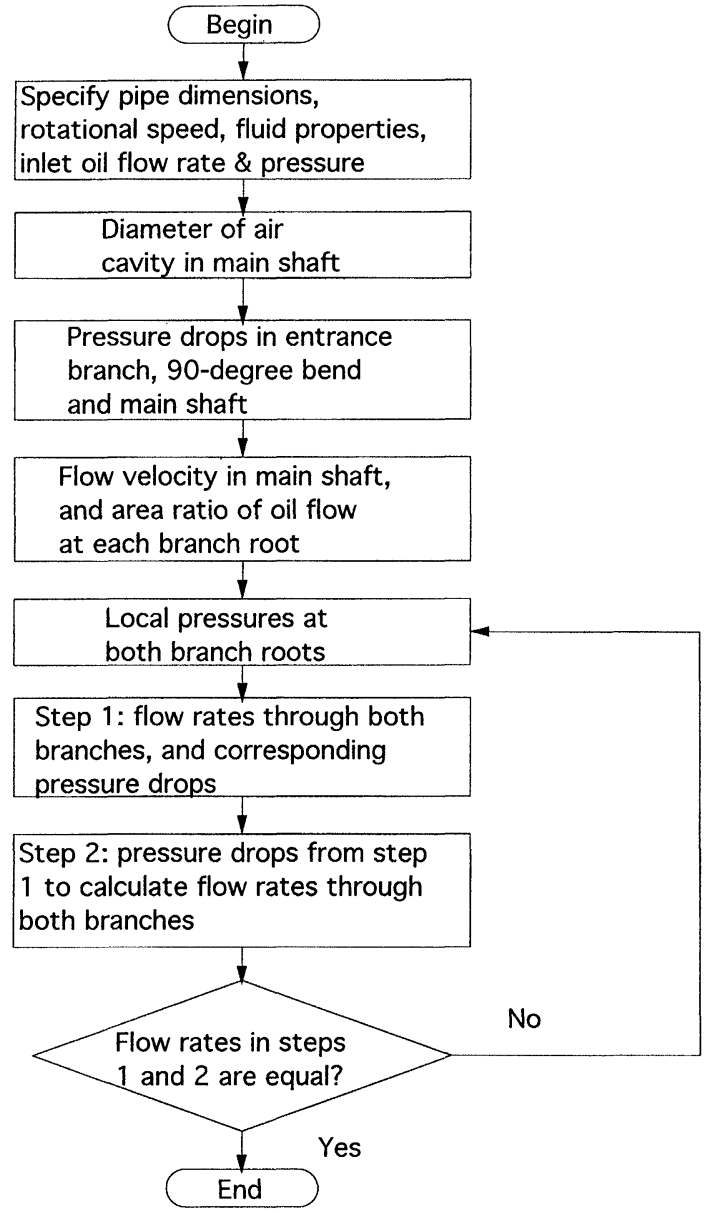

FIGURE 2 Flow chart for annular flow.

The predictions show the abrupt separation of these two oil flow rates at the SF right margin, although the maximum and minimum are overestimated. The modeling for the bubbly and bubbly-slug flow regimes (in short, B\&BF) assumes a gradual growth of the slug, but the growth is rapid and reaches the Branch A root just across the left margin of B\&BF. The modeling also fails at the right margin, implying that a transition occurs. The unacceptable result that the predicted $Q_{\mathrm{B}}$ exceeds the predicted $Q_{\mathrm{A}}$ also confirms the transition to the annular flow regime (in short, AF). The modeling well predicts $Q_{\mathrm{A}}$ and $Q_{\mathrm{B}}$ in $\mathrm{AF}$ and errors are quite small.

In the spin-down process, the modeling fails to predict the significant separation of $Q_{\mathrm{A}}$ and $Q_{\mathrm{B}}$ at the AF left margin. B\&BF reveals the approach of $Q_{\mathrm{A}}$ and $Q_{\mathrm{B}}$ at its left margin, but fails to predict the maximum and minimum, the initial separation, and the final approach. The modeling for SF is accurate because air bubbles released from the upstream slug are carried downstream without blocking the Branch A root.

\section{Test Section \#2 (Fig. 4)}

In the spin-up and spin-down processes, the predicted $Q_{\mathrm{A}}$ and $Q_{\mathrm{B}}$ agree with the measured data, especially in AF. The extremely low $Q_{\mathrm{B}}$ at low $W$ 's is because the centrifugal force here is small compared with the buoyancy force, and is unable to expel the air space which fills Branch B. B\&BF fails to predict $Q_{\mathrm{A}}$ and $Q_{\mathrm{B}}$ at high $W$ 's, but the narrow range of speeds due to the swift growth of the air core practically makes no difference whether these regimes exist. AF accurately predicts the separation of $Q_{\mathrm{A}}$ and $Q_{\mathrm{B}}$ at medium $W$ 's and the approach attempt at high $W$ 's.

\section{CONCLUSIONS}

Two-phase flow through a rotating tube has been modeled to predict both the exit liquid flow rates and pressure drop from the radial inlet port to the exit of the twin branches for both the spin-up and spin-down processes. There exist for distinct flow regimes in the rotating system, depending on rotational speed: single-phase, bubbly, bubbly-slug and annular flows. This model can treat all the four regimes but with certain limitations. It can be applied to improve the design and thus enhance the performance of automatic transmission lines and rotating systems where lubrication is required.

\section{NOMENCLATURE}

A cross-sectional area

$H \quad$ head loss

$K \quad$ minor head loss coefficient 

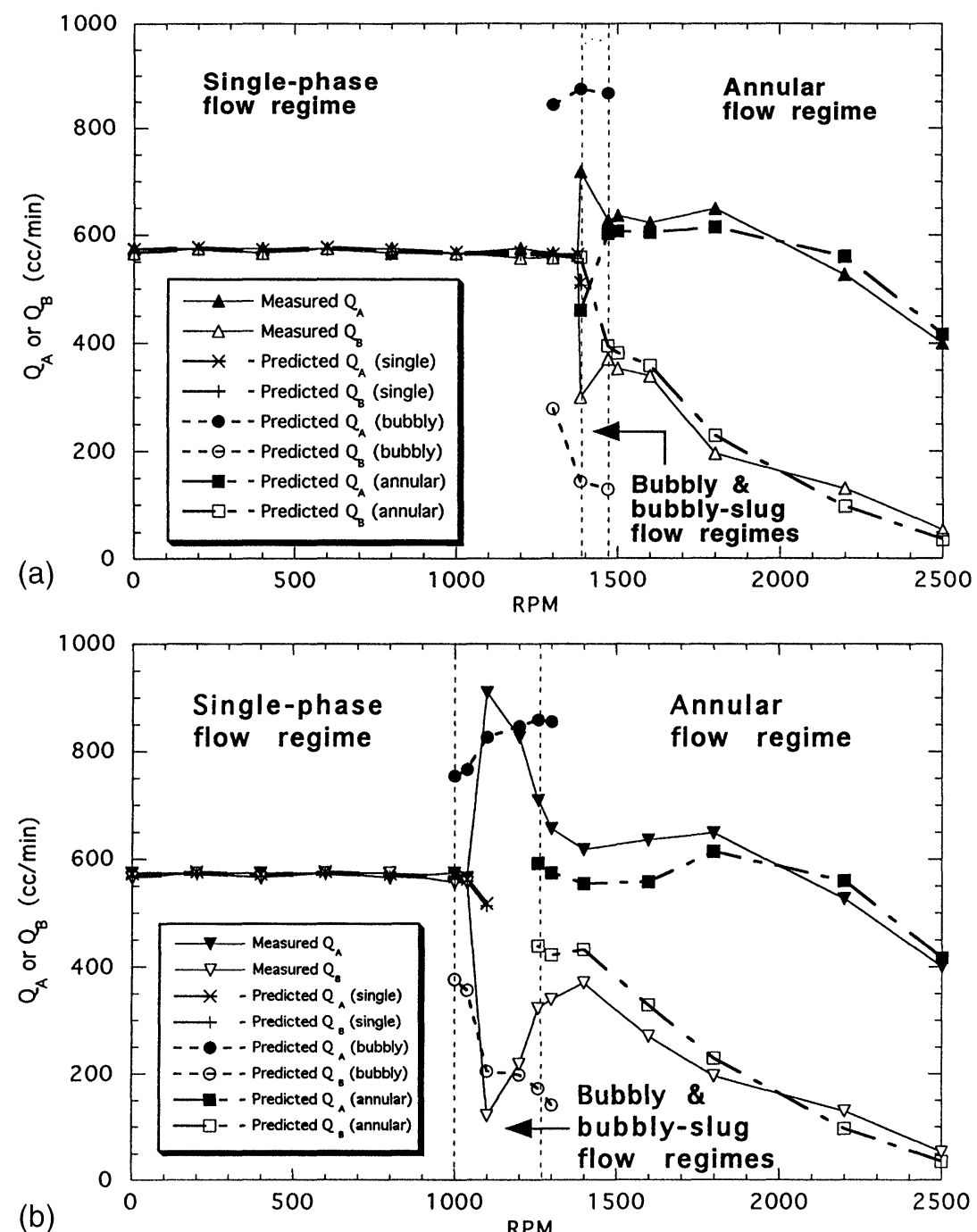

FIGURE 3 (a) Comparison between measured and predicted low oil flow rates through branches of Test Section \#1 in spin-up process. (ID: $\# \mathrm{~A}=3.175 \mathrm{~mm}, \# \mathrm{~B}=3.175 \mathrm{~mm} ; Q_{\mathrm{T}-\mathrm{ini}}=1135.5 \mathrm{~cm}^{3} / \mathrm{min}$.). (b) Comparison between measured and predicted low oil flow rates through branches of Test Section $\# 1$ in spin-down process. (ID: $\# \mathrm{~A}=3.175 \mathrm{~mm}, \# \mathrm{~B}=3.175 \mathrm{~mm} ; Q_{\mathrm{T}-\mathrm{ini}}=1135.5 \mathrm{~cm}^{3} / \mathrm{min}$.).

$L \quad$ length of inlet duct or exit branch

$P \quad$ pressure

$Q \quad$ oil volumetric flow rate

Re Reynolds number $(=2 u r / \nu)$

rotational Reynolds number $\left(=W r_{\text {tube }}^{2} / \nu\right)$

$U$ velocity in vector form

$W \quad$ rotational speed

$f$ head loss friction factor $l \quad$ distances between branches $\mathrm{A}$ and $\mathrm{B}$ and between A and entry radius

$u$ average velocity

$\nu \quad$ kinematic viscosity of oil (torque fluid, $12.99 \mathrm{~mm}^{2} / \mathrm{s}$ at $32^{\circ} \mathrm{C}$ )

$\rho \quad$ density of oil (torque fluid, $815 \mathrm{~kg} / \mathrm{m}^{3}$ at $32^{\circ} \mathrm{C}$ ) 

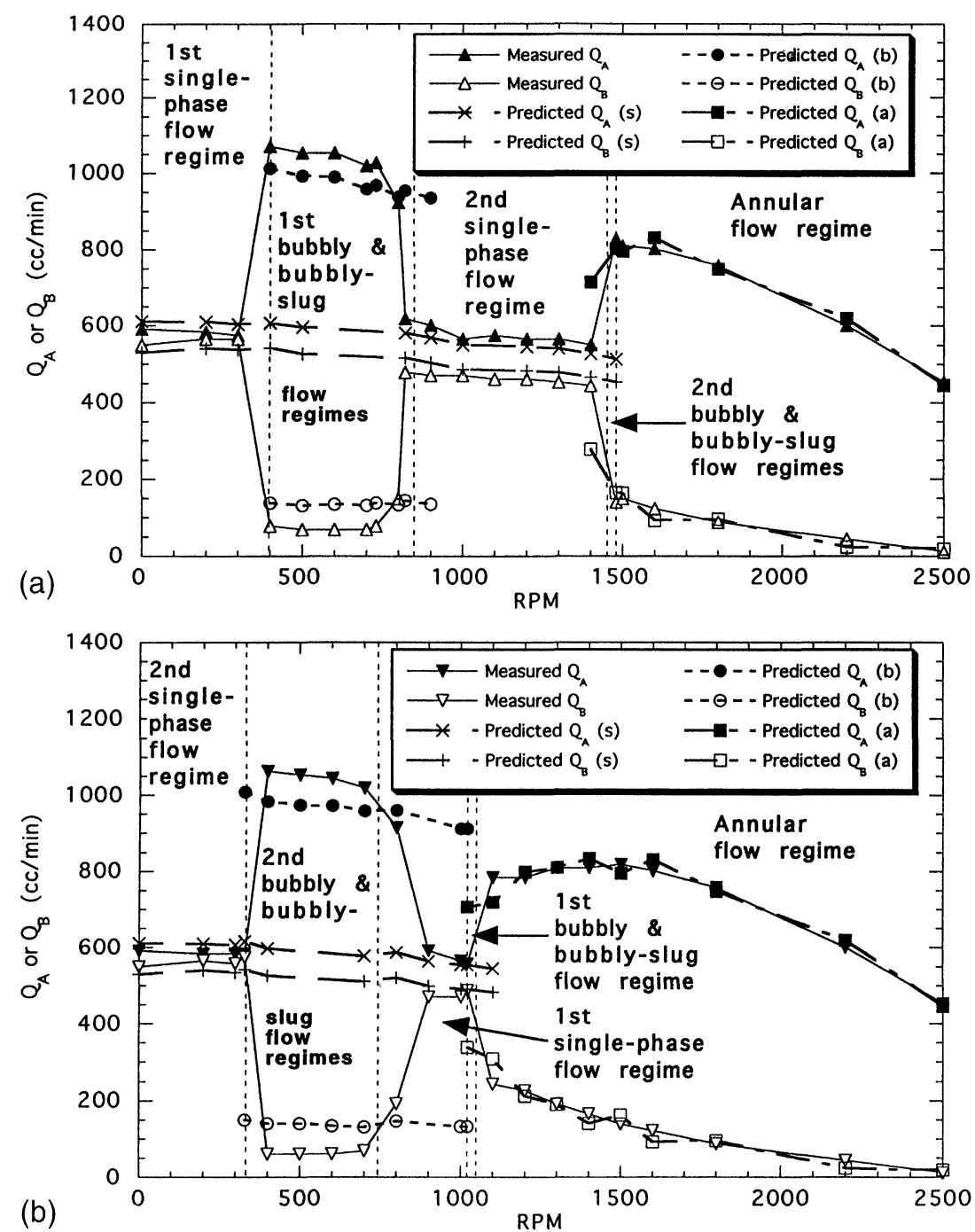

FIGURE 4 (a) Comparison between measured and predicted low oil flow rates through branches of Test Section \#2 in spin-up process. (ID: $\# \mathrm{~A}=6.35 \mathrm{~mm}, \# \mathrm{~B}=6.35 \mathrm{~mm} ; Q_{\mathrm{T}-\mathrm{ini}}=1135.5 \mathrm{~cm}^{3} / \mathrm{min}$.). (b) Comparison between measured and predicted low oil flow rates through branches of Test Section $\# 2$ in spin-down process. (ID: $\# \mathrm{~A}=6.35 \mathrm{~mm}, \# \mathrm{~B}=6.35 \mathrm{~mm} ; Q_{\mathrm{T}-\mathrm{ini}}=1135.5 \mathrm{~cm} / \mathrm{min}$.).

$\begin{array}{ll}\sigma & \text { surface tension } \\ \tau & \text { shear stress }\end{array}$

\section{Subscripts}

$\begin{array}{ll}\text { A } & \text { upstream exit branch } \\ \text { B } & \text { downstream exit branch } \\ \text { G } & \text { gas or air } \\ \text { L } & \text { liquid or oil } \\ \text { T } & \text { total }\end{array}$

dn downstream section

i interface

in entrance branch

ini at stationary state (0 RPM)

o stationary flow

$r$ radial direction

td travel distance

tube horizontal rotating tube

up upstream section 
W tube or branch wall

$\mathrm{x}$ inlet, Branch A or B

$z \quad$ throughflow direction

$\theta \quad$ rotational direction

\section{References}

Backe, W. (1973) Ein Neues Konzept Fuer Hydraulishe Widerstandsseuerungen (New Concept for Hydraulic Resistance Controls), Industrie-Anzeiger, Vol. 95, No. 53, pp. $1137-$ 1141 for part 1, and No. 62, pp. 1431-1434 for part 2 .

Cheng, Sun-Wen and Yang, Wen-Jei (1996) Visualization of oil-cavitation flow in a rotating horizontal tube with twin exit branches, Proceedings of the ASME Fluids Engineering Divivion Summer Meeting, San Diego, USA, July 7-11, 1996, Vol. 4, pp. 17-21.

Cheng, Sun-Wen and Yang, Wen-Jei (1997) Hysteresis in oil flow through a rotating tube with twin exit branches, International Journal of Rotating Machinery, 3(4), 249-258.

Kojima, M., Fukumura, K. and Yasue, H. (1991) A study on the lubricating oil flow in the automatic transmission, SAE paper 910801.

Uchiyama, T., Minemura, K. and Emura, T. (1994) Numerical simulation of bubbly flows in a rotating straight channel using Reynolds stress based on mixing length theory. Nippin Kikai Gakkai Ronbunshu, B. Hen/Transactions of the Japanese Society of Mechanical Engineers, Part B, 60(577), 2967-2975. Wallis, G.B. (1969) One-Dimensional Two-Phase Flow McGraw-Hill, New York, Chapter 11, pp. 316-317. 


\section{ait \\ ENERGY MATERIALS}

M A N E Y publishing

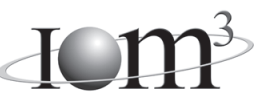

\section{Materials Science \& Engineering for Energy Systems}

Maney Publishing on behalf of the Institute of Materials, Minerals and Mining

The Institute of Materials, Minerals \& Mining

Economic and environmental factors are creating ever greater pressures for the efficient generation, transmission and use of energy. Materials developments are crucial to progress in all these areas: to innovation in design; to extending lifetime and maintenance intervals; and to successful operation in more demanding environments. Drawing together the broad community with interests in these areas, Energy Materials addresses materials needs in future energy generation, transmission, utilisation, conservation and storage. The journal covers thermal generation and gas turbines; renewable power (wind, wave, tidal, hydro, solar and geothermal); fuel cells (low and high temperature); materials issues relevant to biomass and biotechnology; nuclear power generation (fission and fusion); hydrogen generation and storage in the context of the 'hydrogen economy'; and the transmission and storage of the energy produced.

As well as publishing high-quality peer-reviewed research, Energy Materials promotes discussion of issues common to all sectors, through commissioned reviews and commentaries. The journal includes coverage of energy economics and policy, and broader social issues, since the political and legislative context influence research and investment decisions.

\section{CALL FOR PAPERS}

Contributions to the journal should be submitted online at http://ema.edmgr.com

To view the Notes for Contributors please visit: www.maney.co.uk/journals/notes/ema

Upon publication in 2006, this journal will be available via the Ingenta Connect journals service. To view free sample content online visit: www.ingentaconnect.com/content/maney

For further information please contact:

Maney Publishing UK

Tel: +44 (0)113 2497481 Fax: +44 (0)1132486983 Email: subscriptions@maney.co.uk

or

Maney Publishing North America

Tel (toll free): 8662975154 Fax: 6173546875 Email: maney@maneyusa.com

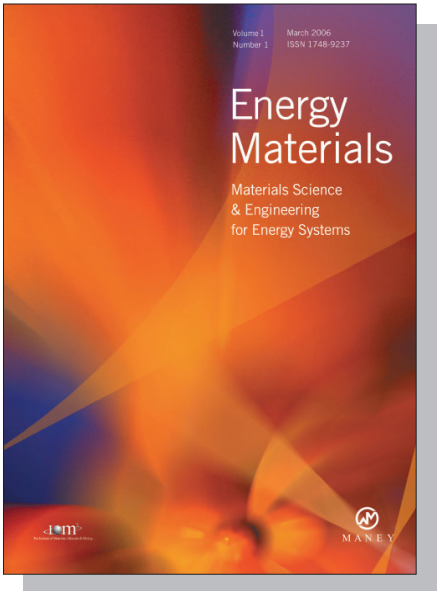

EDITORS

Dr Fujio Abe

NIMS, Japan

Dr John Hald, IPL-MPT, Technical University of Denmark, Denmark

Dr R Viswanathan, EPRI, USA

\section{SUBSCRIPTION INFORMATION}

Volume 1 (2006), 4 issues per year

Print ISSN: 1748-9237 Online ISSN: 1748-9245

Individual rate: $£ 76.00 / U S \$ 141.00$

Institutional rate: $£ 235.00 /$ US $\$ 435.00$

Online-only institutional rate: $£ 199.00 / U S \$ 367.00$

For special $\mathrm{IOM}^{3}$ member rates please email

subscriptions@maney.co.uk

\section{For further information or to subscribe online please visit www.maney.co.uk}



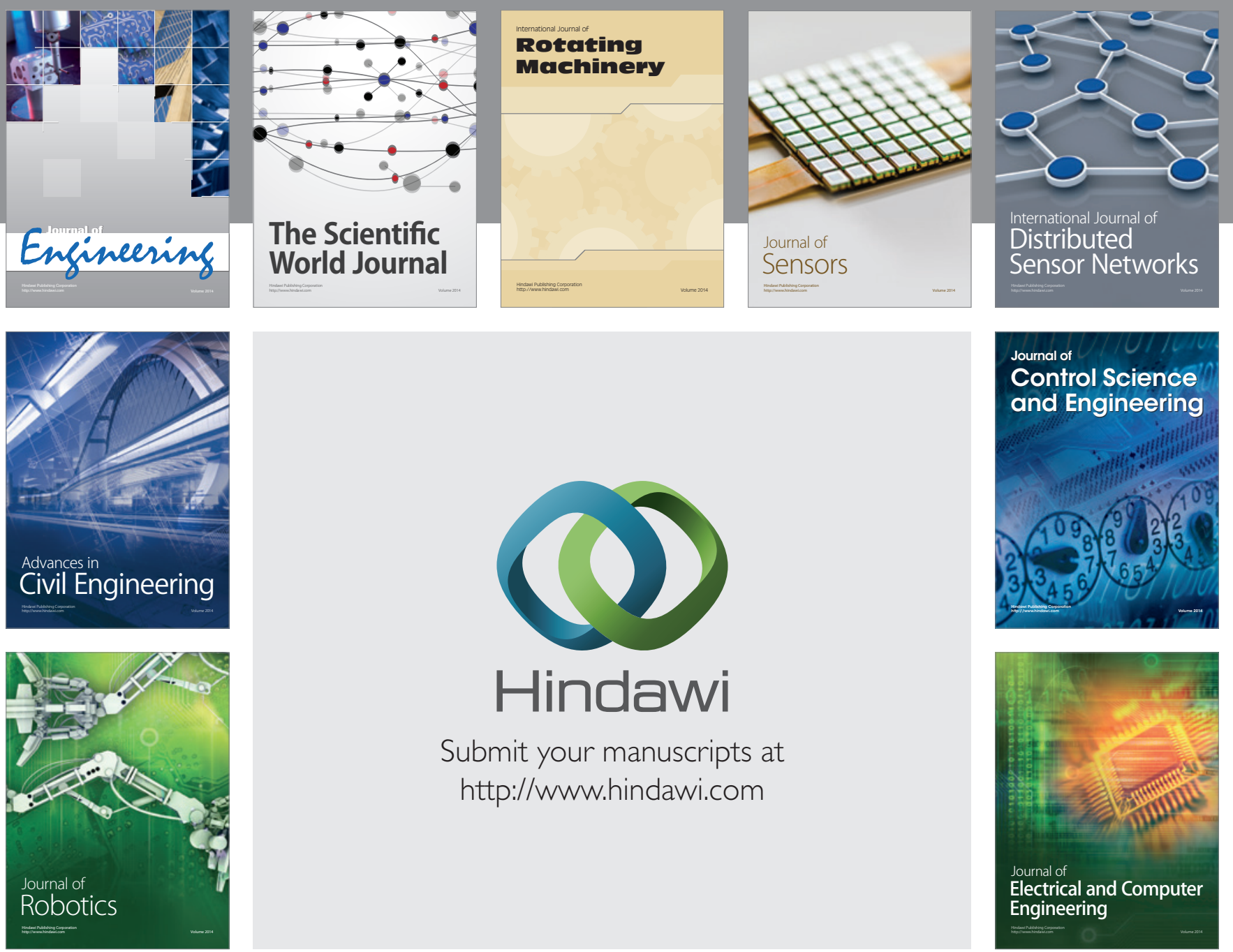

Submit your manuscripts at

http://www.hindawi.com
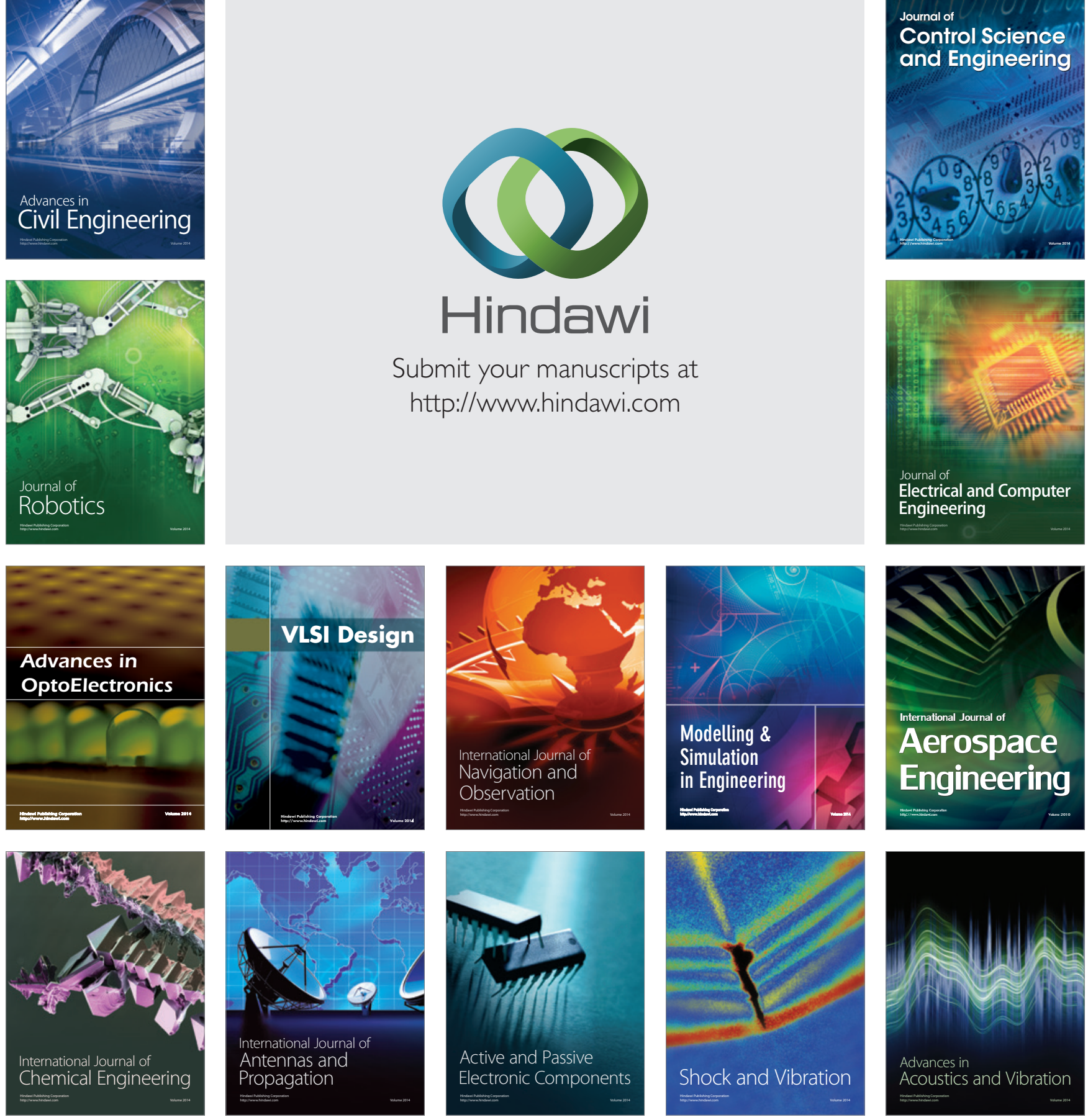